\title{
Preface to the Second Edition
}

We are pleased that Edward Elgar offered us the opportunity to publish a second edition of 'Comparative Tort Law: Global Perspectives'. A few contributions have gone unchanged, because their subjects remained substantially untouched by the passing of time. Others have been significantly revised, including a new author for the essay on the relationships between human rights and tort law, while a few fall somewhere in between the former and the latter. We have been able to cover new areas as well. The second edition has allowed the book to expand considerably its scope, and hopefully its readerships. New chapters are devoted to the challenges of deploying artificial intelligent technologies in compensating personal injuries, and to the tort laws of Brazil, India and Russia. Last but not least, the chapter on Chinese tort law has been updated with the soon to come into force (on January 1, 2021) Chinese Civil Code.

We wish to deeply thank all our contributors for having accepted to deliver such high-quality papers to us, the publisher and the readership.

$M . B \&$ A.J. S.

Trieste - New York, July 2020 
Mauro Bussani and Anthony J. Sebok - 9781789905984 Downloaded from PubFactory at $04 / 26 / 2023$ 07:37:22AM via free access 